\title{
QALYfying the value of life
}

\author{
John Harris Centre for Social Ethics and Policy, University of Manchester
}

This paper argues that the Quality Adjusted Life Year or $Q A L Y$ is fatally flawed as a way of priority setting in health care and of dealing with the problem of scarce resources. In addition to showing why this is so the paper sets out a view of the moral constraints that govern the allocation of health resources and suggests reasons for a new attitude to the health budget.

Against a background of permanently scarce resources it is clearly crucial that such health care resources as are available be not used wastefully. This point is often made in terms of 'efficiency' and it is argued, not implausibly, that to talk of efficiency implies that we are able to distinguish between efficient and inefficient use of health care resources, and hence that we are in some sense able to measure the results of treatment. To do so of course we need a standard of measurement. Traditionally, in life-endangering conditions, that standard has been easy to find. Successful treatment removes the danger to life, or at least postpones it, and so the survival rates of treatment have been regarded as a good indicator of success (1). However, equally clearly, it is also of crucial importance to those treated that the help offered them not only removes the threat to life, but leaves them able to enjoy the remission granted. In short, gives them reasonable quality, as well as extended quantity of life.

A new measure of quality of life which combines length of survival with an attempt to measure the quality of that survival has recently (2) been suggested and is becoming influential. The need for such a measure has been thus described by one of its chief architects: 'We need a simple, versatile, measure of success which incorporates both life expectancy and quality of life, and which reflects the values and ethics of the community served. The "Quality Adjusted Life Year" (QALY) measure fulfils such a role' (3). This is a large claim and an important one, if it can be sustained its consequences for health care will be profound indeed.

\section{Key words}

QALY; equality; civil rights; efficiency; scarce resources.
There are, however, substantial theoretical problems in the development of such a measure, and more important by far, grave dangers of its misuse. I shall argue that the dangers of misuse, which partly derive from inadequacies in the theory which generates them, make this measure itself a life-threatening device. In showing why this is so I shall attempt to say something positive about just what is involved in making scrupulous choices between people in situations of scarce resources, and I will end by saying something about the entitlement to claim in particular circumstances, that resources are indeed scarce.

We must first turn to the task of examining the QALY and the possible consequences of its use in resource allocation. A task incidentally which, because it aims at the identification and eradication of a life-threatening condition, itself (surprisingly perhaps for a philosophical paper) counts also as a piece of medical research (4), which if successful will prove genuinely therapeutic.

\section{The QALY}

\section{WHAT ARE QALYS?}

It is important to be as clear as possible as to just what a QALY is and what it might be used for. I cannot do better than let Alan Williams, the architect of QALYs referred to above, tell you in his own words:

'The essence of a QALY is that it takes a year of healthy life expectancy to be worth one, but regards a year of unhealthy life expectancy as worth less than 1 . Its precise value is lower the worse the quality of life of the unhealthy person (which is what the "quality adjusted" bit is all about). If being dead is worth zero, it is, in principle, possible for a QALY to be negative, ie for the quality of someone's life to be judged worse than being dead.

The general idea is that a beneficial health care activity is one that generates a positive amount of QALYs, and that an efficient health care activity is one where the cost per QALY is as low as it can be. A high priority health care activity is one where the cost-perQALY is low, and a low priority activity is one where cost-per-QALY is high' (5). 
The plausibility of the QALY derives from the idea that 'given the choice, a person would prefer a shorter healthier life to a longer period of survival in a state of severe discomfort and disability' (6). The idea that any rational person would endorse this preference provides the moral and political force behind the QALY. Its acceptability as a measurement of health then depends upon its doing all the theoretical tasks assigned to it, and on its being what people want, or would want, for themselves.

\section{HOW WILL QALYS BE USED?}

There are two ways in which QALYs might be used. One is unexceptionable and useful, and fully in line with the assumptions which give QALYs their plausibility. The other is none of these.

QALYs might be used to determine which of rival therapies to give to a particular patient or which procedure to use to treat a particular condition. Clearly the one generating the most QALYs will be the better bet, both for the patient and for a society with scarce resources. However, QALYs might also be used to determine not what treatment to give these patients, but which group of patients to treat, or which conditions to give priority in the allocation of health care resources. It is clear that it is this latter use which Williams has in mind, for he specifically cites as one of the rewards of the development of QALYs, their use in 'priority setting in the health care system in general' (7). It is this use which is likely to be of greatest interest to all those concerned with efficiency in the health service. And it is for this reason that it is likely to be both the most influential and to have the most farreaching effects. It is this use which is I believe positively dangerous and morally indefensible. Why?

\section{WHAT'S WRONG WITH QALYS?}

It is crucial to realise that the whole plausibility of QALYs depends upon our accepting that they simply involve the generalisation of the 'truth' (8) that 'given the choice a person would prefer a shorter healthier life to a longer period of survival in a state of severe discomfort'. On this view giving priority to treatments which produce more QALYs or for which the cost-perQALY is low, is both efficient and is also what the community as a whole, and those at risk in particular, actually want. But whereas it follows from the fact that given the choice a person would prefer a shorter healthier life to a longer one of severe discomfort, that the best treatment for that person is the one yielding the most QALYs, it does not follow that treatments yielding more QALYs are preferable to treatments yielding fewer where different people are to receive the treatments. That is to say, while it follows from the fact (if it is a fact) that I and everyone else would prefer to have, say one year of healthy life rather than three years of severe discomfort, that we value healthy existence more than uncomfortable existence for ourselves, it does not follow that where the choice is between three years of discomfort for $m e$ or immediate death on the one hand, and one year of health for you, or immediate death on the other, that I am somehow committed to the judgement that you ought to be saved rather than me.

Suppose that Andrew, Brian, Charles, Dorothy, Elizabeth, Fiona and George all have zero lifeexpectancy without treatment, but with medical care, all but George will get one year complete remission and George will get seven years' remission. The costs of treating each of the six are equal but George's operation costs five times as much as the cost of the other operations. It does not follow that even if each person, if asked, would prefer seven years' remission to one for themselves, that they are all committed to the view that George should be treated rather than that they should. Nor does it follow that this is a preference that society should endorse. But it is the preference that QALYs dictate.

Such a policy does not value life or lives at all, for it is individuals who are alive, and individuals who lose their lives. And when they do the loss is principally their loss. The value of someone's life is, primarily and overwhelmingly, its value to him or her; the wrong done when an individual's life is cut short is a wrong to that individual. The victim of a murder or a fatal accident is the person who loses his life. A disaster is the greater the more victims there are, the more lives that are lost. A society which values the lives of its citizens is one which tries to ensure that as few of them die prematurely (that is when their lives could continue) as possible. Giving value to life-years or QALYs, has the effect in this case of sacrificing six lives for one. If each of the seven wants to go on living for as long as he or she can, if each values the prospective term of remission available, then to choose between them on the basis of life-years (quality adjusted or not), is in this case to give no value to the lives of six people.

\section{THE ETHICS OF QALYS}

Although we might be right to claim that people are not committed to QALYs as a measurement of health simply in virtue of their acceptance of the idea that each would prefer to have more QALYs rather than fewer for themselves, are there good moral reasons why QALYs should none the less be accepted?

The idea, which is at the root of both democratic theory and of most conceptions of justice, that each person is as morally important as any other and hence, that the life and interests of each is to be given equal weight, while apparently referred to and employed by Williams plays no part at all in the theory of QALYs. That which is to be given equal weight is not persons and their interests and preferences, but qualityadjusted life-years. And giving priority to the manufacture of QALYs can mean them all going to a few at the expense of the interests and wishes of the many. It will also mean that all available resources will tend to be deployed to assist those who will thereby gain the maximum QALYs - the young. 


\section{THE FALLACY OF VALUING TIME}

There is a general problem for any position which holds that time-spans are of equal value no matter who gets them, and it stems from the practice of valuing life-units (life-years) rather than people's lives.

If what matters most is the number of life-years the world contains, then the best thing we can do is devote our resources to increasing the population. Birth control, abortion and sex education come out very badly on the QALY scale of priorities.

In the face of a problem like this, the QALY advocate must insist that what he wants is to select the therapy that generates the most QALYs for those people who already exist, and not simply to create the maximum number of QALYs. But if it is people and not units of life-span that matter, if the QALY is advocated because it is seen as a moral and efficient way to fulfil our obligation to provide care for our fellows, then it does matter who gets the QALYs - because it matters how people are treated. And this is where the ageism of QALYS and their other discriminatory features become important.

\section{QALYS ARE AGEIST}

Maximising QALYs involves an implicit and comprehensive ageist bias. For saving the lives of younger people is, other things being equal, always likely to be productive of more QALYs than saving older people. Thus on the QALY arithmetic we always have a reason to prefer, for example, neonatal or paediatric care to all 'later' branches of medicine. This is because any calculation of the life-years generated for a particular patient by a particular therapy, must be based on the life expectancy of that patient. The older a patient is when treated, the fewer the life-years that can be achieved by the therapy.

It is true that QALYs dictate that we prefer people, not simply who have more life expectancy, but rather people who have more life expectancy to be gained from treatment. But wherever treatment saves a life, and this will be frequently, for quite simple treatments, like a timely antibiotic, can be life-saving, it will, other things being equal, be the case that younger people have more life expectancy to gain from the treatment than do older people.

\section{AGEISM AND AID}

Another problem with such a view is that it seems to imply, for example, that when looking at societies from the outside, those with a lower average age have somehow a greater claim on our aid. This might have important consequences in looking at questions concerning aid policy on a global scale. Of course it is true that a society's having a low average age might be a good indicator of its need for help, in that it would imply that people were dying prematurely. However, we can imagine a society suffering a disaster which killed off many of its young people (war perhaps) and which was consequently left with a high average age but was equally deserving of aid despite the fact that such aid would inevitably benefit the old. If QALYs were applied to the decision as to whether to provide aid to this society or another much less populous and perhaps with less pressing problems, but with a more normal age distribution, the 'older' society might well be judged 'not worth' helping.

\section{QALYS CAN BE RACIST AND SEXIST}

If a 'high priority health care activity is one where the cost-per-QALY is low, and a low priority activity is one where cost-per-QALY is high' then people who just happen to have conditions which are relatively cheap to treat are always going to be given priority over those who happen to have conditions which are relatively expensive to treat. This will inevitably involve not only a systematic pattern of disadvantage to particular groups of patients, or to people afflicted with particular diseases or conditions, but perhaps also a systematic preference for the survival of some kinds of patients at the expense of others. We usually think that justice requires that we do not allow certain sections of the community or certain types of individual to become the victims of systematic disadvantage and that there are good moral reasons for doing justice, not just when it costs us nothing or when it is convenient or efficient, but also and particularly, when there is a price to be paid. We'll return shortly to this crucial issue of justice, but it is important to be clear about the possible social consequences of adopting QALYs.

Adoption of QALYs as the rationale for the distribution of health care resources may, for the above reasons, involve the creation of a systematic pattern of preference for certain racial groups or for a particular gender or, what is the same thing, a certain pattern of discrimination against such groups. Suppose that medical statistics reveal that say women, or Asian males, do better than others after a particular operation or course of treatment, or, that a particular condition that has a very poor prognosis in terms of QALYs afflicts only Jews, or gay men. Such statistics abound and the adoption of QALYs may well dictate very severe and systematic discrimination against groups identified primarily by race, gender or colour, in the allocation of health resources, where it turns out that such groups are vulnerable to conditions that are not QALY-efficient (9).

Of course it is just a fact of life and far from sinister that different races and genders are subject to different conditions, but the problem is that QALYs may tend to reinforce and perpetuate these 'structural' disadvantages.

\section{DOUBLE JEOPARDY}

Relatedly, suppose a particular terminal condition was treatable, and would, with treatment, give indefinite remission but with a very poor quality of life. Suppose for example that if an accident victim were treated, he would survive, but with paraplegia. This might always 
cash out at fewer QALYs than a condition which with treatment would give a patient perfect remission for about five years after which the patient would die. Suppose that both candidates wanted to go on living as long as they could and so both wanted, equally fervently, to be given the treatment that would save their lives. Is it clear that the candidate with most QALYs on offer should always and inevitably be the one to have priority? To judge so would be to count the paraplegic's desire to live the life that was available to him as of less value than his rival's - what price equal weight to the preferences of each individual?

This feature of QALYs involves a sort of double jeopardy. QALYs dictate that because an individual is unfortunate, because she has once become a victim of disaster, we are required to visit upon her a second and perhaps graver misfortune. The first disaster leaves her with a poor quality of life and QALYs then require that in virtue of this she be ruled out as a candidate for lifesaving treatment, or at best, that she be given little or no chance of benefiting from what little amelioration her condition admits of. Her first disaster leaves her with a poor quality of life and when she presents herself for help, along come QALYs and finish her off!

\section{LIFE-SAVING AND LIFE-ENHANCING}

A distinction, consideration of which is long overdue, is that between treatments which are life-saving (or death-postponing) and those which are simply lifeenhancing, in the sense that they improve the quality of life without improving life-expectancy. Most people think, and for good as well as for prudential reasons, that life-saving has priority over life-enhancement and that we should first allocate resources to those areas where they are immediately needed to save life and only when this has been done should the remainder be allocated to alleviating non-fatal conditions. Of course there are exceptions even here and some conditions, while not life-threatening, are so painful that to leave someone in a state of suffering while we attend even to the saving of life, would constitute unjustifiable cruelty. But these situations are rare and for the vast majority of cases we judge that life-saving should have priority.

It is important to notice that QALYs make no such distinction between types of treatment. Defenders of QALYs often cite with pride the example of hipreplacement operations which are more QALY-efficient than say kidney dialysis (10). While the difficulty of choosing between treating very different groups of patients, some of whom need treatment simply to stay alive, while others need it to relieve pain and distress, is clearly very acute, and while it may be that lifesaving should not always have priority over lifeenhancement, the dangers of adopting QALYs which regard only one dimension of the rival claims, and a dubious one at that, as morally relevant, should be clear enough.

There is surely something fishy about QALYs. They can hardly form 'an appropriate basis for health service policy'. Can we give an account of just where they are deficient from the point of view of morality? We can, and indeed we have already started to do so. In addition to their other problems, QALYs and their use for priority setting in health care or for choosing not which treatment to give these patients, but for selecting which patients or conditions to treat, involve profound injustice, and if implemented would constitute a denial of the most basic civil rights. Why is this?

\section{Moral constraints}

One general constraint that is widely accepted and that I think most people would judge should govern life and death decisions, is the idea that many people believe expresses the values animating the health service as a whole. These are the belief that the life and health of each person matters, and matters as much as that of any other and that each person is entitled to be treated with equal concern and respect both in the way health resources are distributed and in the way they are treated generally by health care professionals, however much their personal circumstances may differ from that of others.

This popular belief about the values which animate the health service depends on a more abstract view about the source and structure of such values and it is worth saying just a bit about this now.

\section{THE VALUE OF LIFE}

One such value is the value of life itself. Our own continued existence as individuals is the sine qua non of almost everything. So long as we want to go on living, practically everything we value or want depends upon our continued existence. This is one reason why we generally give priority to life-saving over lifeenhancing.

To think that life is valuable, that in most circumstances, the worst thing that can happen to an individual is that she lose her life when this need not happen, and that the worst thing we can do is make decisions, a consequence of which, is that others die prematurely, we must think that each life is valuable. Each life counts for one and that is why more count for more. For this reason we should give priority to saving as many lives as we can, not as many life-years (11).

One important point must be emphasised at this stage. We talk of 'life-saving' but of course this must always be understood as 'death-postponing'. Normally we want to have our death postponed for as long as possible but where what's possible is the gaining of only very short periods of remission, hours or days, these may not be worth having. Even those who are moribund in this sense can usually recognise this fact, particularly if they are aware that the cost of postponing their death for a few hours or days at the most will mean suffering or death for others. However, even brief remission can be valuable in enabling the individual to put her affairs in order, make farewells 
and so on, and this can be important. It is for the individual to decide whether the remission that she can be granted is worth having. This is a delicate point that needs more discussion than I can give it here. However, inasmuch as QALYs do not help us to understand the features of a short and painful remission that might none the less make that period of vital importance to the individual, perhaps in terms of making something worthwhile out of her life as a whole, the difficulties of these sorts of circumstances, while real enough, do not undermine the case against QALYs (12).

\section{TREATING PEOPLE AS EQUALS}

If each life counts for one, then the life of each has the same value as that of any. This is why accepting the value of life generates a principle of equality. This principle does not of course entail that we treat each person equally in the sense of treating each person the same. This would be absurd and self-defeating. What it does involve is the idea that we treat each person with the same concern and respect. An illustration provided by Ronald Dworkin, whose work on equality informs this entire discussion, best illustrates this point: 'If I have two children, and one is dying from a disease that is making the other uncomfortale, I do not show equal concern if I flip a coin to decide which should have the remaining dose of a drug' (13).

It is not surprising then that the pattern of protections for individuals that we think of in terms of civil rights (14) centres on the physical protection of the individual and of her most fundamental interests. One of the prime functions of the State is to protect the lives and fundamental interests of its citizens and to treat each citizen as the equal of any other. This is why the State has a basic obligation, inter alia, to treat all citizens as equals in the distribution of benefits and opportunities which affect their civil rights. The State must, in short, treat each citizen with equal concern and respect. The civil rights generated by this principle will of course include rights to the allocation of such things as legal protections and educational and health care resources. And this requirement that the State uphold the civil rights of citizens and deal justly between them, means that it must not choose between individuals, or permit choices to be made between individuals, that abridge their civil rights or in ways that attack their right to treatment as equals.

Whatever else this means, it certainly means that a society, through its public institutions, is not entitled to discriminate between individuals in ways that mean life or death for them on grounds which count the lives or fundamental interests of some as worth less than those of others. If for example some people were given life-saving treatment in preference to others because they had a better quality of life than those others, or more dependants and friends, or because they were considered more useful, this would amount to regarding such people as more valuable than others on that account. Indeed it would be tantamount, literally, to sacrificing the lives of others so that they might continue to live (15).

Because my own life would be better and even of more value to me if I were healthier, fitter, had more money, more friends, more lovers, more children, more life expectancy, more everything I want, it does not follow that others are entitled to decide that because I lack some or all of these things I am less entitled to health care resources, or less worthy to receive those resources, than are others, or that those resources would somehow be wasted on me.

\section{CIVIL RIGHTS}

I have spoken in terms of civil rights advisedly. If we think of the parallel with our attitude to the system of criminal justice the reasons will be obvious. We think that the liberty of the subject is of fundamental importance and that no one should be wrongfully detained. This is why there are no financial constraints on society's obligation to attempt to ensure equality before the law. An individual is entitled to a fair trial no matter what the financial costs to society (and they can be substantial). We don't adopt rubrics for the allocation of justice which dictate that only those for whom justice can be cheaply provided will receive it. And the reason is that something of fundamental importance is at stake - the liberty of the individual.

In health care something of arguably greater importance is often at stake - the very life of the individual. Indeed, since the abolition of capital punishment, the importance of seeing that individuals' civil rights are respected in health care is pre-eminent.

\section{DISCRIMINATION}

The only way to deal between individuals in a way which treats them as equals when resources are scarce, is to allocate those resources in a way which exhibits no preference. To discriminate between people on the grounds of quality of life, or QALY, or life-expectancy, is as unwarranted as it would be to discriminate on the grounds of race or gender.

So, the problem of choosing how to allocate scarce resources is simple. And by that of course I mean 'theoretically simple', not that the decisions will be easy to make or that it will be anything but agonisingly difficult actually to determine, however justly, who should live and who should die. Life-saving resources should simply be allocated in ways which do not violate the individual's entitlement to be treated as the equal of any other individual in the society: and that means the individual's entitlement to have his interests and desires weighed at the same value as those of anyone else. The QALY and the other bases of preference we have considered are irrelevant.

If health professionals are forced by the scarcity of resources, to choose, they should avoid unjust discrimination. But how are they to do this?

\section{Just distribution}

If there were a satisfactory principle or theory of just 
distribution now would be the time to recommend its use (14). Unfortunately there is not a satisfactory principle available. The task is to allocate resources between competing claimants in a way that does not violate the individual's entitlement to be treated as the equal of any other individual - and that means her entitlement to have her fundamental interests and desires weighed at the same value as those of anyone else. The QALY and other quality-of-life criteria are, as we have seen, both dangerous and irrelevant as are considerations based on life-expectancy or on 'lifeyears' generated by the proposed treatment. If health professionals are forced by the scarcity of resources to choose, not whether to treat but who to treat, they must avoid any method that amounts to unjust discrimination.

I do not pretend that the task of achieving this will be an easy one, nor that I have any satisfactory solution. I do have views on how to approach a solution, but the development of those ideas is a task for another occasion (12). I will be content for the moment if I have shown that QALYs are not the answer and that efforts to find one will have to take a different direction.

\section{DEFENSIVE MEDICINE}

While it is true that resources will always be limited it is far from clear that resources for health care are justifiably as limited as they are sometimes made to appear. People within health care are too often forced to consider simply the question of the best way of allocating the health care budget, and consequently are forced to compete with each other for resources. Where lives are at stake however, the issue is a moral issue which faces the whole community, and in such circumstances, is one which calls for a fundamental reappraisal of priorities. The question should therefore be posed in terms, not of the health care budget alone, but of the national budget (16). If this is done it will be clearer that it is simply not true that the resources necessary to save the lives of citizens are not available. Since the citizens in question are in real and present danger of death, the issue of the allocation of resources to life-saving is naturally one of, among other things, national defence. Clearly then health professionals who require additional resources simply to save the lives of citizens, have a prior and priority claim on the defence budget.

QALYs encourage the idea that the task for health economics is to find more efficient ways of doing the wrong thing - in this case sacrificing the lives of patients who could be saved. All people concerned with health care should have as their priority defensive medicine: defending their patients against unjust and lethal policies, and guarding themselves against devices that tend to disguise the immorality of what they are asked to do.

\section{PRIORITY IN LIFE-SAVING}

It is implausible to suppose that we cannot deploy vastly greater resources than we do at present to save the lives of all those in immediate mortal danger. It should be only in exceptional circumstances unforeseen and massive disasters for example - that we cannot achieve this. However, in such circumstances our first duty is to try to save the maximum number of lives possible. This is because, since each person's life is valuable, and since we are committed to treating each person with the same concern and respect that we show to any, we must preserve the lives of as many individuals as we can. To fail to do so would be to value at zero the lives and fundamental interests of those extra people we could, but do not, save. Where we cannot save all, we should select those who are not to be saved in a way that shows no unjust preference.

We should be very clear that the obligation to save as many lives as possible is not the obligation to save as many lives as we can cheaply or economically save. Among the sorts of disasters that force us to choose between lives, is not the disaster of overspending a limited health care budget!

There are multifarious examples of what I have in mind here and just a couple must suffice to illustrate the point. Suppose, as is often the case, providing health care in one region of a country (17) is more expensive than doing so in another, or where saving the lives of people with particular conditions, is radically more expensive than other life-saving procedures, and a given health care budget won't run to the saving of all. Then any formula employed to choose priorities should do just that. Instead of attempting to measure the value of people's lives and select which are worth saving, any rubric for resource allocation should examine the national budget afresh to see whether there are any headings of expenditure that are more important to the community than rescuing citizens in mortal danger. For only if all other claims on funding are plausibly more important than that, is it true that resources for life-saving are limited.

\section{CONCLUSION}

The principle of equal access to health care is sustained by the very same reasons that sustain both the principle of equality before the law and the civil rights required to defend the freedom of the indivual. These are rightly considered so important that no limit is set on the cost of sustaining them. Equal access to health care is of equal importance and should be accorded the same priority for analogous reasons. Indeed, since the abolition of capital punishment, due process of law is arguably of less vital importance than is access to health care. We have seen that QALYs involve denying that the life and health of each citizen is as important as that of any. If, for example, we applied the QALY principle to the administration of criminal justice we might find that those with little life expectancy would have less to gain from securing their freedom and therefore should not be defended at all, or perhaps given a jury trial only if not in competition for such things with younger or fitter fellow citizens. 
A recent $B B C$ television programme calculated (18) that if a health authority had $£ 200,000$ to spend it would get 10 QALYs from dialysis of kidney patients, 266 QALYs from hip-replacement operations or 1197 QALYs from anti-smoking propaganda. While this information is undoubtedly useful and while advice to stop smoking is an important part of health care, we should be wary of a formula which seems to dictate that such a health authority would use its resources most efficiently if it abandoned hip replacements and dialysis in favour of advice to stop smoking.

Fohn Harris is Senior Lecturer in Philosophy in the Department of Education and Research Director of the Centre For Social Ethics and Policy, University of Manchester.

\section{Acknowledgement}

This is a revised version of a paper presented to the British Medical Association Annual Scientific Meeting, Oxford, April 1986.

As so often, I must thank my colleague Dr Mary Lobjoit for her generous medical advice. The fact that, like certain patients, I am apt to misunderstand this advice is of course my own fault. Thank are also due to Don Evans, Alan Williams and the editors of the Fournal of Medical Ethics for helpful comments.

\section{References and notes}

(1) See the excellent discussion of the recent history of this line of thought in the Office of Health Economics publication The measurement of health London, 1985.

(2) Williams A. Economics of coronary artery bypass grafting. British medical journal 1985; 291; and his contribution to the article, Centre eight - in search of efficiency. Health and social service journal 1985. These are by no means the first such attempts. See reference (1).

(3) Williams A. The value of QALYs. Health and social service journal 1985.

(4) I mention this in case anyone should think that it is only medical scientists who do medical research.

(5) See reference (3): 3.

(6) See reference (1): 16

(7) See reference (3): 5 , and reference (3).

(8) I'll assume this can be described as 'true' for the sake of argument.

(9) I am indebted to Dr S G Potts for pointing out to me some of these statistics and for other helpful comments.

(10) For examples see reference (1) and reference (2).

(11) See Parfit D. Innumerate ethics. Philosophy and public affairs 1978; 7, 4. Parfit's arguments provide a detailed defence of the principle that each is to count for one.

(12) I consider these problems in more detail in my: eQALYty. In: Byrne P, ed.King's College studies. London: King's Fund Press, 1987/8. Forthcoming.

(13) Dworkin R. Taking rights seriously. London: Duckworth, 1977: 227.

(14) I do not of course mean to imply that there are such things as rights, merely that our use of the language of rights captures the special importance we attach to certain freedoms and protections. The term 'civil rights' is used here as a 'term of art' referring to those freedoms and protections that are customarily classed as "civil rights'.

(15) For an interesting attempt to fill this gap see Dworkin $\mathbf{R}$. What is equality? Philosophy and public affairs 1981; 4 and 5 .

(16) And of course the international budget; see my The value of life. London: Routledge \& Kegan Paul 1985: chapter 3.

(17) See Townsend P, Davidson N, eds. Inequalities in health: the Black Report. Harmondsworth, Penguin: 1982.

(18) BBC 1. The heart of the matter 1986, Oct.

\section{Response: QALYfying the value of life}

\section{Alan Williams University of York}

The essence of Harris's position can be encapsulated in the following three propositions:

1) Health care priorities should not be influenced by any other consideration than keeping people alive;

2) Everyone has an equal right to be kept alive if that is what they wish, irrespective of how poor their prognosis is, and no matter what sacrifices others have to bear as a consequence;

3) When allocating health care resources, we must not discriminate between people, not even according to their differential capacity to benefit from treatment.

My position, which he attacks, can be encapsulated in the following three propositions:

1) Health care priorities should be influenced by our capacity both to increase life expectation and to improve people's quality of life.

2) A particular improvement in health should be regarded as of equal value, no matter who gets it, and should be provided unless it prevents a greater improvement being offered to someone else.

3 ) It is the responsibility of everyone to discriminate wherever necessary to ensure that our limited resources go where they will do the most good.

At the end of the day we simply have to stand up and be counted as to which set of principles we wish to have underpin the way the health care system works.

The rest of Harris's points are really detail and I will deal with them on a subsequent occasion when I have had a chance to study his promised way forward, for that may help to dispel the very serious doubts I hold at present as to whether he realises the grave implications of the position he has adopted.

Alan Williams is Professor of Economics at the University of York.

\section{Key words}

QALY; equality; civil rights; efficiency; scarce resources. 